\title{
Study of Morphometric Aspects of Eri Silkworm (Samia ricini D.) reared on the host plant
}

\author{
Dipika Doloi, Department of Zoology, Cotton University, Guwahati, Assam \& India, \\ doloidpka31@yahoo.com
}

\begin{abstract}
The environmental conditions play a significant role and influence the quantitative and qualitative characters of silkworm such as larval length, larval breadth, larval weight and larval duration. Larvae of Eri silkworm (Samia ricini D.) were reared on Castor leaves (Ricinus communis). The data that were recorded for larval length (cm) from first to fifth instar are $0.76 \pm 0.003 ; 1.49 \pm 0.023 ; 3.09 \pm 0.020 ; 4.39 \pm 0.04$ and $6.57 \pm 0.04$ respectively, for larval breadth $(\mathrm{cm})$ are $0.122 \pm 0.007 ; 0.24 \pm 0.0 ; 0.46 \pm 0.0 ; 0.74 \pm 0.0$ and $1.14 \pm 0.0$ respectively and for larval weight $(\mathrm{g})$ are $0.007 \pm 0.01 ; 0.033 \pm 0.02 ; 0.37 \pm 0.01 ; 1.07 \pm 0.02$ and $3.74 \pm 0.03$ respectively and the larval period of the reared larvae lasted for about 20 days.
\end{abstract}

Keywords — Eri silkworm, instar, larval breadth, larval length, larval weight, rearing.

\section{INTRODUCTION}

Insects that are commercially used to produce silk are the mulberry silk moth (Bombyx mori) and non-mulberry silk moths (Antheraea sp. and Samia sp.). Silk is the finest form of fibre among all the forms of textile fibre, natural or manmade. It is rightly termed as the queen of textiles. Assam is the largest state in Northeast India, situated in the foothill of south-eastern Himalayas, and comprises the Brahmaputra Valley and the Barak Valley sideways with the Karbi Anglong and Dima Hasao districts with an area of 30,285 square miles $\left(78,440 \mathrm{~km}^{2}\right)$. Traditionally, sericulture is a major source of livelihood in the state of Assam. Sericulture has been practiced in Assam from time immemorial and continues to be an important labour-intensive and agrobased cottage industry. According to Thangavelu et al. $1988^{[7]}$, the favourable conditions like humidity, rainfall, acidic soil required by the food plants of this silkworm are only found in Assam. The State accounts for the highest production of non-mulberry silk, muga, and eri in the country (Choudhury, 1982) ${ }^{[1]}$. Silk culture is practiced in 11,281 Assamese villages at present and provides employment to 6.5 lakh households (Ramesha and Kirsur, $1998)^{[6]}$.

Silk produced by Samia ricini D. is called eri silk. The heavy rainfall and humid atmosphere are suitable for eri culture. The distribution of eri silk worm is confined to Assam and bordering districts of West Bengal. In Assam, eri culture is popular among its village side and tribal region, leading to extensive cottage industry in that area. Eri is multivoltine, domesticated and reared indoors, for five to six times per year. As eri silk moth can tolerate environmental adversities and very much disease resistant, they can grow rapidly. The duration of life cycle varies with season, i.e., 18 days in summer and 45 days in winter. It is adjusted with temperature variation from $12^{\circ} \mathrm{C}$ to $37^{\circ} \mathrm{C}$ and $\mathrm{RH}$ variation from $80 \%$ to $100 \%$. Eri worms are polyphagous having primary as well as secondary food plants. Primary food plants are Ricinus communis (Vern. Castor) and Heteropanax fragrans (Vern. Kesseru). The secondary food plants are Manihot utilissima (Vern. Tapioca), Evodia flaxinifolia (Vern. Payam), Plumeria acutifolia (Vern. Plum) and Carica papaya (Vern. Papaya). The quality of feed plays a remarkable role for growth and development of the silkworm and ultimately on the economic traits of cocoons ${ }^{[2]}$. All the food plants are not equally good for eri silkworm rearing and the silkworm show different behaviour, when reared on different food plants ${ }^{[3]}$. The optimum temperature for growth of young stage eri silkworm is about $26-28^{\circ} \mathrm{C}$, with relative humidity of $85-90 \%$, whereas for later stage worm slightly cooler temperatures of $24-26^{\circ} \mathrm{C}$ and relative humidity of $70-80 \%$ are required.

Study of developmental stages of a species is very essential. The traits of developmental stages are vital tools for taxonomic identity of the species. Therefore, systematic research on Eri silkworm is very essential for the sustained development of this industry. Thus, in this context, the present study has been conducted with the aim to study the morphometric parameters (length, breadth and weight) and also larval duration of different instars of larvae of Eri silkworm.

\section{MATERIALS AND METHODOLOGY}

\section{A. Rearing}

Taxonomic position of experimental silkworm:

Kingdom - Animalia

Phylum - Arthropoda

Class - Insecta 
Order - Lepidoptera

Genus - Samia

Species - S. ricini

Disease-free eggs of Samia ricini, were obtained from the Eri Silkworm Seed Production Centre, Bongara, Assam (Fig. 1). They were reared indoors on the leaves of castor (Ricinus communis) plant (Fig. 2). The eri silkworm rearing practices suggested by Patil and Savanurmath $(1994)^{[5]}$ was followed in rearing eri silkworm for the experiment. Two techniques were used for rearing the larvae - (a) surface (tray) rearing technique and (b) bunch hanging technique ${ }^{[4]}$. But, before rearing, rooms were disinfected and the eggs were disinfected with 2 percent formalin solution and were kept for hatching in paper boxes. The colour of the eggs changes to blue on the day prior to hatching. The larvae hatched after about 5-6 days. The newly hatched larvae were transferred to rearing trays (made of paper; dimension $20.5 \times 13 \mathrm{~cm}$ ) using fine 0 number camel hair brush over which few tender castor leaves were spread (Fig. 3). The rearing trays were covered with nylon net of fine mesh. Then when the larvae attained $1^{\text {st }}$ instar, they were transferred to trays, made up of bamboo (diameter about $20 \mathrm{~cm}$ ). Initially the larvae after hatching were given soft leaves 3 to 4 times a day (for $1^{\text {st }}, 2^{\text {nd }}$ and $3^{\text {rd }}$ instar larvae). Then the frequency was increased to 5 to 6 times a day for $4^{\text {th }}$ and $5^{\text {th }}$ instar larvae and fed with matured leaves. Bed cleaning was carried out at regular interval. For $1^{\text {st }}$ instar, bed cleaning was done once, twice during $2^{\text {nd }}$ instar, thrice in $3^{\text {rd }}$ and $4^{\text {th }}$ instar and daily once in the $5^{\text {th }}$ instar. Bed cleaning was done in morning hours manually. The $1^{\text {st }}, 2^{\text {nd }}$ and $3^{\text {rd }}$ instar larvae were reared using surface rearing technique in the bamboo tray of diameter $44 \mathrm{~cm}$ (Fig. 4). While, the $4^{\text {th }}$ and $5^{\text {th }}$ instar larvae were reared using bunch hanging method in which bunches of the host plant leaves were hung pointing downward on a bamboo pole which was placed parallel to the ground surface using rope fixed to the roof of the rearing room (Fig. 5). The fully matured $5^{\text {th }}$ instar larvae (Fig. 6) stops feeding, discharges out the contents of gut and starts searching for a proper place to spin the cocoon. At this stage, the matured larvae were picked up and transferred to mountages. The mountages used were dried banana leaves.

\section{B. Morphometric Analysis}

Morphometric analysis of the Eri larvae reared on Castor leaves (Ricinus communis) were done to determine its growth and development. The parameters that were considered to determine the growth and development, were, length (using measuring scale), breadth (using vernier calliper) and weight (using Shimadzu electronic weighing balance, readability - $0.001 \mathrm{~g}$ ) of the larvae. The measurements were taken for all larval stages from first to fifth instar. There were 5 replicates and each replicate consisted of 10 individuals. The length of each of the instars (1st, 2nd, 3rd, 4th and 5th) were taken by measuring scale. The breadth of each of the instars were taken by vernier caliper. The weight of each of the instars were taken by using Shimadzu electronic weighing balance, readability $0.001 \mathrm{~g}$.

The larval duration was also calculated for all the larval instars, from the day of hatching to the matured $5^{\text {th }}$ instar larvae. 5 replicates were made consisting of 10 larvae each to study the larval duration.

\section{Figures}

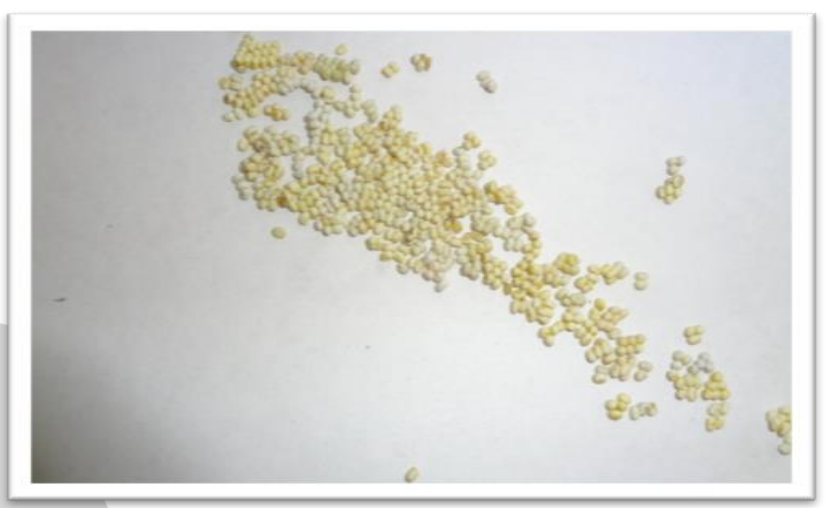

Fig. 1: Eggs of Eri

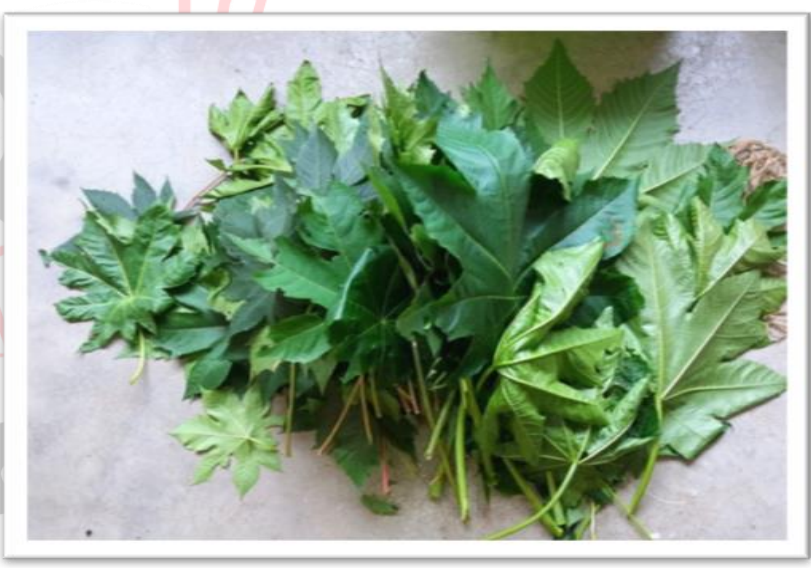

Fig. 2: Castor leaves

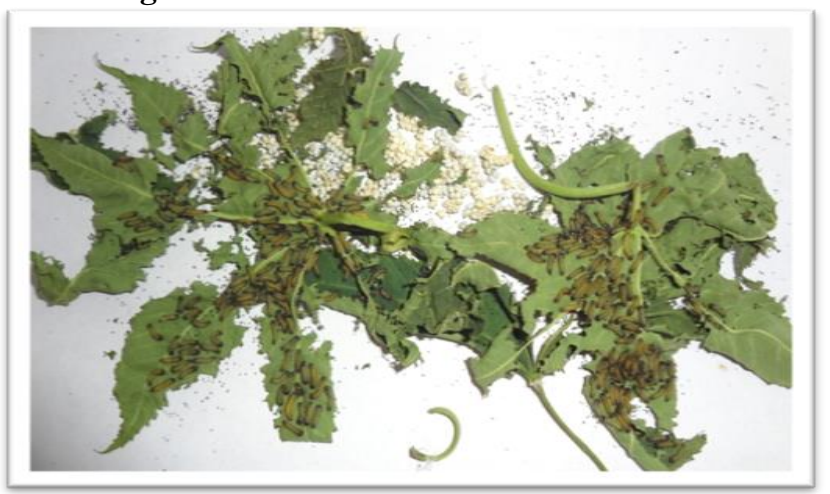

Fig. 3: Larvae just after hatching 


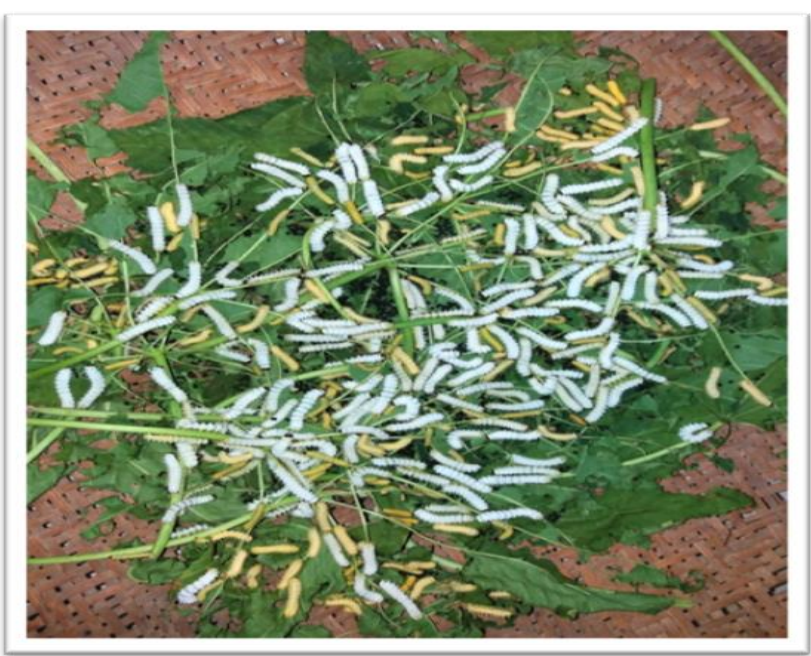

Fig. 4: Surface (tray) rearing technique for $1^{\text {st }}, 2^{\text {nd }}$ and $3^{\text {rd }}$ instar

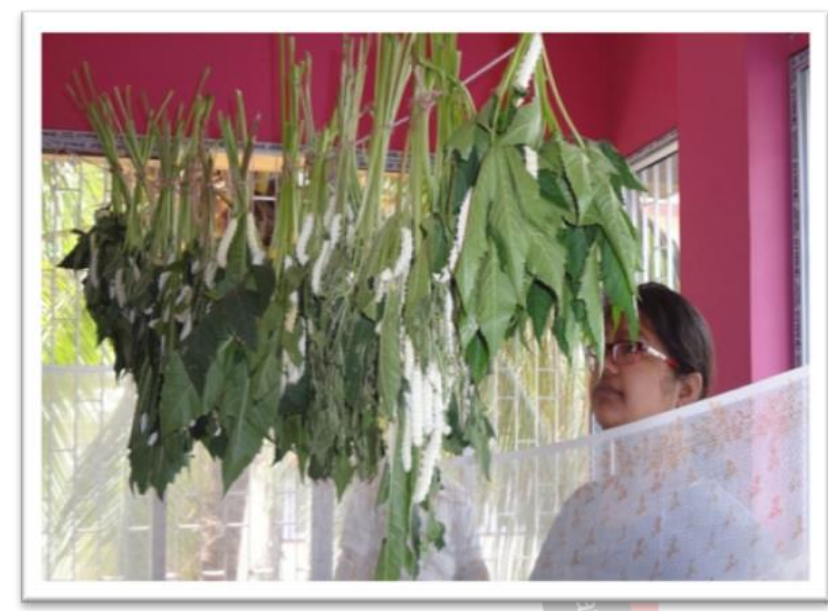

Fig. 5: Bunch hanging technique of $4^{\text {th }}$ and $5^{\text {th }}$ instar

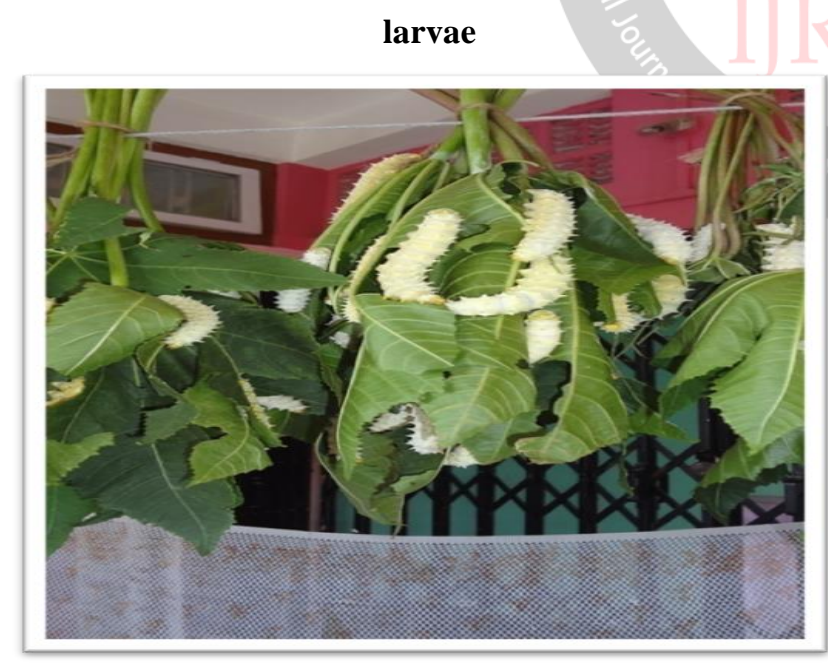

Fig. 6: Matured $5^{\text {th }}$ instar larvae

\section{ReSUlts}

The present study was undertaken to observe certain larval parameters of Eri silkworm when reared on its host plant. Accordingly, an investigation was carried out during the rearing (March-April) 2018. Rearing was conducted in indoor conditions on castor leaves (Ricinus communis) and the data were recorded for further analysis.

\subsection{Larval length}

Table 1: Larval length $(\mathrm{cm})$ of eri silkworm

\begin{tabular}{|c|c|c|c|c|c|c|}
\hline \multirow{2}{*}{$\begin{array}{l}\text { LARVAL } \\
\text { STAGES }\end{array}$} & \multicolumn{5}{|c|}{ REPLICATES $^{*}$} & \multirow{2}{*}{$\begin{array}{c}\text { MEAN } \\
(\mathrm{cm}) \pm \\
\text { SE }\end{array}$} \\
\hline & R1 & R2 & R3 & $\mathrm{R} 4$ & R5 & \\
\hline L1 & 0.76 & 0.76 & 0.77 & 0.76 & 0.77 & $\begin{array}{l}0.76 \pm \\
0.003\end{array}$ \\
\hline L2 & 1.43 & 1.50 & 1.50 & 1.51 & 1.47 & $\begin{array}{l}1.49 \pm \\
0.023\end{array}$ \\
\hline L3 & 3.11 & 3.1 & 3 & 3.1 & 3.14 & $\begin{array}{l}3.09 \pm \\
0.020\end{array}$ \\
\hline L4 & 3.96 & 4.19 & 4.55 & 4.63 & 4.62 & $\begin{array}{c}4.39 \pm \\
0.04\end{array}$ \\
\hline L5 & 6.12 & 6.45 & 6.9 & 6.67 & 6.73 & $\begin{array}{c}6.57 \pm \\
0.04\end{array}$ \\
\hline
\end{tabular}

Note: *Each replicate consisted of 10 insect

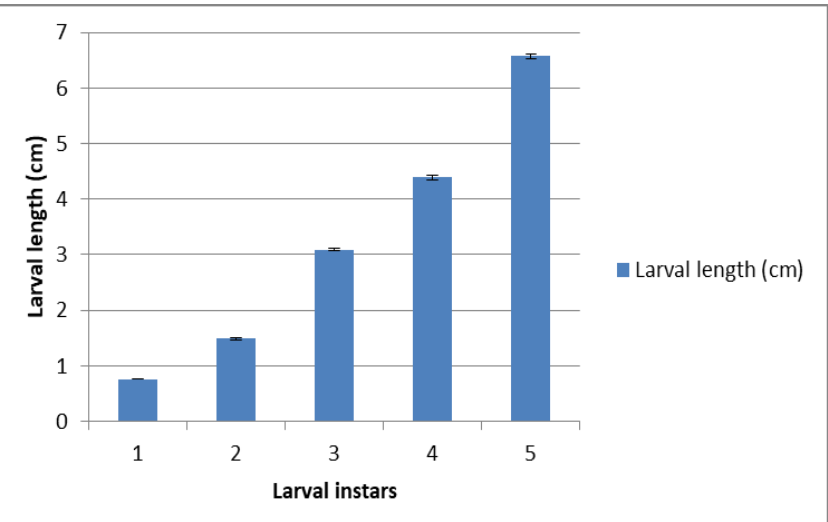

Fig. 7: Showing larval length $(\mathrm{cm})$ of eri silkworm

There was increase in the larval length $(\mathrm{cm})$ with every instar, $1^{\text {st }}$ being just $0.76 \mathrm{~cm}$ and the last instar measured nearly $6.5 \mathrm{~cm}$ (Table 1 and Fig. 7). There was a gradual increase in the larval length from first instar to third instar but an abrupt increase in length was observed at $4^{\text {th }}$ instar.

\subsection{Larval breadth}

Table 2: Larval breadth $(\mathrm{cm})$ of eri silkworm

\begin{tabular}{|c|c|c|c|c|c|c|}
\hline \multirow{2}{*}{$\begin{array}{l}\text { LARVAL } \\
\text { STAGES }\end{array}$} & \multicolumn{5}{|c|}{ REPLICATES* } & \multirow{2}{*}{$\begin{array}{c}\text { MEAN } \\
(\mathrm{cm}) \pm \\
\text { SE }\end{array}$} \\
\hline & $\mathrm{R} 1$ & $\mathrm{R} 2$ & R3 & $\mathrm{R} 4$ & R5 & \\
\hline L1 & 0.105 & 0.108 & 0.137 & 0.135 & 0.125 & $\begin{array}{c}0.122 \pm \\
0.007\end{array}$ \\
\hline L2 & 0.24 & 0.24 & 0.25 & 0.24 & 0.24 & $\begin{array}{c}0.24 \pm \\
0.0\end{array}$ \\
\hline L3 & 0.46 & 0.46 & 0.47 & 0.46 & 0.47 & $\begin{array}{c}0.46 \pm \\
0.0\end{array}$ \\
\hline $\mathrm{L} 4$ & 0.743 & 0.735 & 0.738 & 0.738 & 0.747 & $\begin{array}{c}0.74 \pm \\
0.0\end{array}$ \\
\hline L5 & 1.14 & 1.14 & 1.13 & 1.15 & 1.14 & $\begin{array}{c}1.14 \pm \\
0.0\end{array}$ \\
\hline
\end{tabular}

Note: *Each replicate consisted of 10 insect 


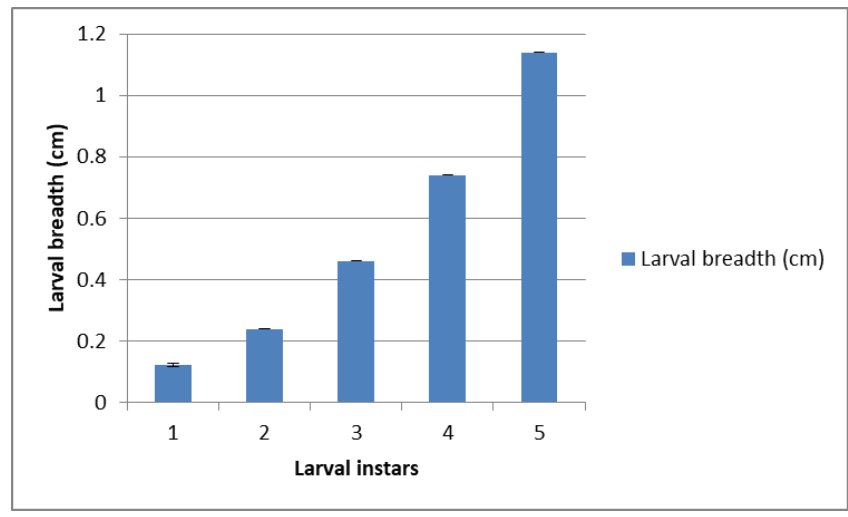

Fig. 8: Showing larval breadth $(\mathrm{cm})$ of eri silkworm

There was not much difference in the larval breadth of first and the second instar larvae (Table 2 and Fig. 8) and also between third and fourth instar indicating that growth is more evident in the larval length than in its thickness at each larval instar. The larval thickness increased from $0.12 \mathrm{~cm}$ to $\sim 1.14 \mathrm{~cm}$ thickness from first to fifth instar.

\subsection{Larval weight}

Table 3: Larval weight (g) of eri silkworm

\begin{tabular}{|c|c|c|c|c|c|c|}
\hline \multirow{2}{*}{$\begin{array}{c}\text { LARVAL } \\
\text { STAGES }\end{array}$} & $\mathrm{R} 1$ & $\mathrm{R} 2$ & $\mathrm{R} 3$ & $\mathrm{R} 4$ & $\mathrm{R} 5$ & $\begin{array}{c}\text { REAN } \\
(\mathrm{g}) \pm \mathrm{SE}\end{array}$ \\
\cline { 2 - 7 } & 0.007 & 0.007 & 0.007 & 0.007 & 0.007 & $\begin{array}{c}0.007 \pm \\
0.01\end{array}$ \\
\hline L1 & 0.033 & 0.033 & 0.033 & 0.033 & 0.033 & $\begin{array}{c}0.033 \pm \\
0.02\end{array}$ \\
\hline L3 & 0.36 & 0.41 & 0.36 & 0.34 & 0.38 & $0.37 \pm$ \\
& 1.05 & 1.02 & 1.16 & 1.07 & 1.07 & $\begin{array}{c}1.07 \pm \\
0.02\end{array}$ \\
\hline L4 & & & & & & 0.01 \\
\hline L5 & 2.71 & 3.79 & 4.06 & 4.02 & 4.12 & $\begin{array}{c}3.74 \pm \\
0.03\end{array}$ \\
\hline
\end{tabular}

Note: *Each replicate consisted of 10 insect

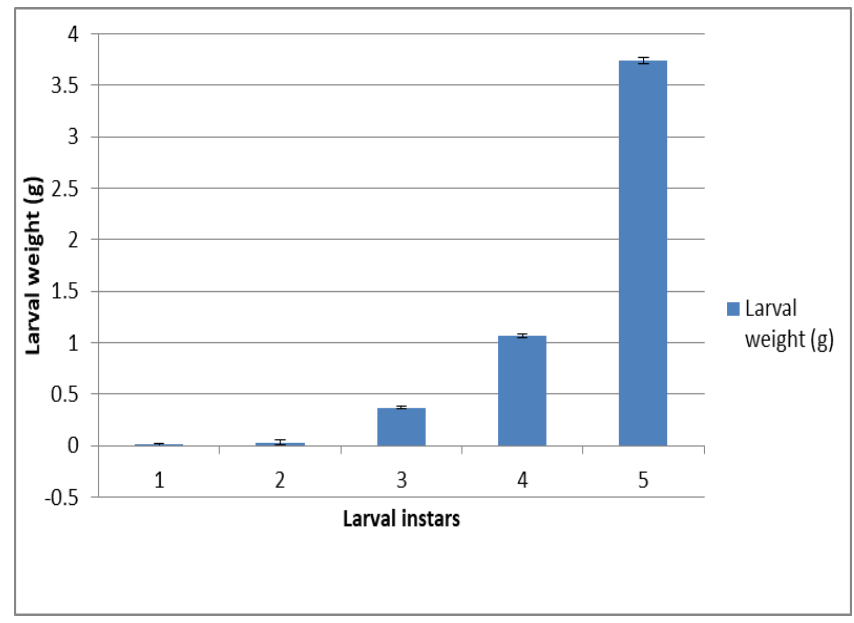

Fig. 9: Showing larval weight (g) of eri silkworm

There was a gradual increase in the larval weight from $1^{\text {st }}$ instar to $4^{\text {th }}$ instar and abrupt increase in the weight in the $5^{\text {th }}$ instar (Table 3 and Fig. 9).

\subsection{Larval duration}

Table 4: Larval duration (days) of eri silkworm

\begin{tabular}{|c|c|}
\hline Instar & Duration (days) \\
\hline $1^{\text {st }}$ instar & 4 days \\
\hline $2^{\text {nd }}$ instar & 4 days \\
\hline $3^{\text {rd }}$ instar & 3 days \\
\hline $4^{\text {th }}$ instar & 3 days \\
\hline $5^{\text {th }}$ instar & 6 days \\
\hline
\end{tabular}

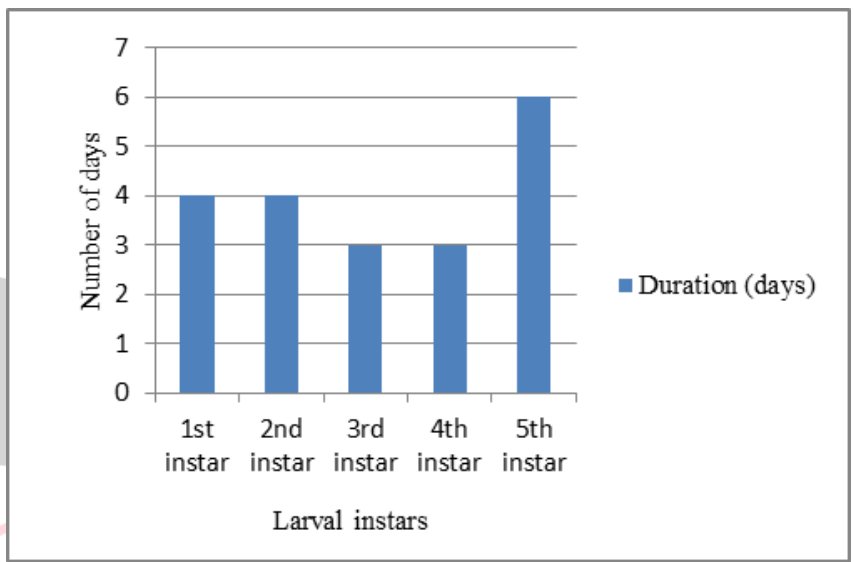

Fig. 10: Showing larval duration (days) of eri silkworm

The larval period of the reared larvae lasted for about 20 days (Table 4 and Fig. 10).

\section{DISCUSSION}

There was increase in the larval length $(\mathrm{cm})$ with every instar, $1^{\text {st }}$ being just $0.76 \mathrm{~cm}$ and the last instar measured nearly $6.5 \mathrm{~cm}$ (Table 1 and Fig. 7). There was a gradual increase in the larval length from first instar to third instar but an abrupt increase in length was observed at $4^{\text {th }}$ instar. Larval length and hence the resulting cocoon is an index of the quality of the silk produced. The findings of Yaligar (2014) regarding the length of eri silkworm on castor plants are comparable to our results.

There was not much difference in the larval breadth of first and the second instar larvae (Table 2 and Fig. 8) and also between third and fourth instar indicating that growth is more evident in the larval length than in its thickness at each larval instar. The larval thickness increased from $0.12 \mathrm{~cm}$ to $\sim 1.14 \mathrm{~cm}$ thickness from first to fifth instar.

There was a gradual increase in the larval weight from $1^{\text {st }}$ instar to $4^{\text {th }}$ instar and abrupt increase in the weight in the $5^{\text {th }}$ instar (Table 3 and Fig. 9). Our results corroborates with the findings of Yaligar (2014) where there was also an abrupt increase from $3^{\text {rd }}$ to $4^{\text {th }}$,i.e., 1.59 to $2.66 \mathrm{~g}$ and $4^{\text {th }}$ to $5^{\text {th }}$ instar, i.e., 2.66 to $6.31 \mathrm{~g}$. The increase in food consumption from the fourth instar onwards might have resulted in sudden increase in length and weight at $4^{\text {th }}$ and 
$5^{\text {th }}$ instar. This weight gain indicates that larval metabolic rate increases as they have to store excess food to prepare itself to enter into the pupal stage where all the feeding activities will be suspended.

The larval period of the reared larvae lasted for about 20 days (Table 4 and Fig. 10). Our results differ from the findings of Yaligar (2014) where he observed the total larval duration to be nearly 17 days.

\section{Conclusion}

India is a tropical country and environmental conditions are the limiting factors of eri silkworm rearing. Majority of eri silkworm rearers encounters the various environmental problems and lose their crops or produce inferior quality of cocoon and silk. Based on the experiments and findings, the larval weight, duration, length and breadth depends on environmental and geographical conditions. Therefore, in different environmental and geographical conditions, the effect of food plants on the growth parameters and other economic parameters may vary. Studies were conducted during the months of March - April, to have a hands on training or experience on silkworm rearing and to study its various biological aspects and also to understand various morphometric experiments. This work can further be carried out in future for advanced research, to understand its silk production, difference in the rearing seasons, etc.

\section{ACKNOWLEDGMENT}

The author is grateful to Eri Silkworm Seed Production Centre, Bongara, Assam, India and Department of Zoology, Cotton University for supporting with lab and space facilities in completing this project work.

\section{REFERENCES}

[1] Choudhury S.N. 1982. Muga Silk Industry, Directorate of Sericulture, Government of Assam, Shilong (Meghalaya), India.

[2] Hazarika U., Barah A. and Chakravorty R. 2005. Physiological and biological response of castor (Ricinus communis Linn.) to application of NPK and their correlation with economic parameters of eri silkworm (Samia ricini DONOVAN). In: Proceeding of $20^{\text {th }}$ Congress of the International sericulture commission volume II, sec, 3 Non-mulberry silkworms, Bangalore India. 94-98.

[3] Kumar R. and Gangwar S.K. 2010. Impact of varietal feeding on Samia ricini Donovan in spring and autumn season of Uttar Pradesh. ARPN Journal of Agricultural and Biological Science; 5(3).

[4] Meth T. and Gogoi H. 2016. Rearing Of Eri Silkworm (Samia cynthia ricini Boisd.) (Lepidoptera: Saturniidae) In Arunachal Pradesh: A Study In
Papumpare District. Journal of Bioresources 3(1): 4652.

[5] Naik M.C. 2008. Growth, Development and Economic Cocoon Parameters of Eri silkworm Samia cynthia ricini Boisduval on New Hosts. Thesis.

[6] Patil G.M. and Savanurmath C.J., 1994. Eri silkworm - The poorman's friend. Indian Silk, 33(4): 41-45.

[7] Ramesha M.N., Kirsur M.V. 1998. Global Cooperation for wild silk development. Indian Silk. 37(8):5-12.

[8] Sarmah M.C., Rahman S.A.S. and Barah A. 2010. Traditional practices and terminologies in Muga and Eri culture. Indian Journal of Traditional Knowledge. 9(3): 448-452.

[9] Thangavelu K., Chakravarty A.K., Bhagawati A.K. and Isa Md. 1988. Hand Book of Muga culture, CSB, Bangalore. 102: 9-11.

[10] Yaligar M. 2014. Rearing performance of eri silkworm Samia cynthia ricini Boisduval on different species of Termanalia and its impact on cocoon quality. Thesis.

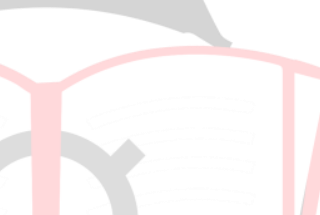

